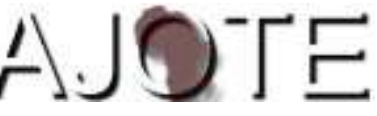

Africa Journal of Teacher Education

ISSN 1916-7822. A Journal of Spread Corporation

Vol. 6 No. $12017 \quad$ Pages 96-118

\title{
Language Supportive Teaching and Textbooks (LSTT) for Bilingual Classrooms Mathematics Teaching and Learning in Tanzania
}

\author{
Francis William \\ Senior Lecturer \\ The University of Dodoma, Tanzania \\ Jesse J. Ndabakurane \\ Assistant Lecturer \\ The University of Dodoma, Tanzania
}

\begin{abstract}
The aim of this study was to assess the impact on teaching and learning using the LSTT (Language Supportive Teaching and Textbooks) project's bilingual Mathematics textbook chapters among Form One students in selected rural community secondary schools in Tanzania. LSTT project was introduced in Tanzania in 2013 to enhance language supportive teaching among the disadvantaged rural groups identified as less competent in foreign languages. The study employed both quantitative and qualitative approaches in data collection and analysis. It employed a bilingual approach whereby Kiswahili was used as a resource in learning mathematical concepts in English language. Its major findings indicated that the students' posttest performance in Mathematics was higher in Dodoma and Lindi Regions compared to their pretest performance. The study concluded that having been oriented through LSTT textbook, the students were likely to start doing the exercises in the textbook without the facilitator's or researcher's support. Evidently, most of the students gained confidence and interest in Mathematics, having used the user friendly LSTT material.
\end{abstract}

Keywords: LSTT Project, Bilingual Classrooms, Mathematics Teaching and Learning 


\section{Introduction}

In Tanzania, English was taught in Standard Five following the opening of Middle Schools in the1950s. In 1958, it was then taught in the primary schools only from Standard III (Allen, 2008). Currently, English language is used for teaching in secondary schools, teacher training colleges at diploma level, and polytechnics and colleges of higher education in Tanzania (MOEVT, 2014). While English was taught as a compulsory subject in public primary schools ${ }^{1}$ (MOEVT, 2014), in 1995, it became both the subject and language of instruction in English medium primary schools although the government has not been ready to admit this, thus permitting an ambiguous situation (Swilla, 2009). Swilla's view is backed up by MOEVT's statement that English language was used for teaching in some schools (MOEVT, 2014). However, the Education Amendment Act of 1995 allowed only two government schools namely Olympio and Arusha, and other nine private schools to use English as a medium of instruction (Rugemalira, 2005). Currently, English is being taught as a compulsory subject in public primary schools whereas it is both the subject and language of instruction in all English medium primary schools ${ }^{2}$ and post-primary education.

Before joining the post-primary education, some students pass through the public primary schools where the medium of instruction (MoI) is Kiswahili although English is the only MoI at the secondary school level. On the other hand, other students go through English medium primary schools where the teaching is done in English and consequently, they find it easier to cope with the secondary education since they already have exposure to English. The former group is rather forced to learn through the language in which they lack prior practical experience and are thus disadvantaged and denied the right to appropriate knowledge. Using English as the sole MoI connotes 'English-only' as a medium of instruction policy in English classes. The studies have investigated different challenges facing English teaching in secondary schools in Tanzania. William (2012), Qorro (2006), Malekela (2006), and Galabawa and Senkoro (2006) have investigated different challenges facing English teaching in secondary schools in Tanzania.

These studies have identified lack of adequate school facilities, lack of effective teaching, and poor learning approaches as limitations to students effectively learning English. Lwaitama

\footnotetext{
${ }^{1}$ In Tanzanian context, these are primary schools whose medium of instruction is Kis wahili.

${ }^{2}$ These are primary schools which use English as the medium of instruction. In Tanzanian context, English medium primary schools are composed of baby, middle, and pre-standard one classes; and standard one to standard seven classes.
} 
and Galabawa (2008) observed that both learners and teachers in community-based secondary schools face serious deficiencies in their mastery of English as the MoI and subject. English language teaching in secondary schools is also hampered by the high difficulty level English textbooks (Qorro, 2006; EdQual, 2010; and Barret, Mtana, Osaki and Rubagumya (2014). They noted that the difficulty level of the books surpassed the students' low entry comprehending ability. EdQual (2010) recommends that language use in textbooks needs to be at the level that learners understand and demands that textbook design for learners learning through European languages to guarantee the textbooks' accessibility notably for disadvantaged language learners. Overcrowded classes is another challenge facing English learning and teaching in Tanzanian schools. In most community based secondary schools, classes have up to 90 students (Ndabakurane, 2012). Such classes limit the application of Communicative Approach (CA) as required in the newly introduced 2005 secondary school syllabus. Sane (2011) observes that teachers find it hard to use the approach in their extremely overcrowded classes and consequently resort to the lecturing method. According to Allen (2008), the teaching of English in Tanzania seems to have lost whatever 'backbone' it previously had, and standards have been compromised.

Deciding on what is the appropriate language of instruction in Tanzania has been a challenge and has attracted the attention of different stakeholders, particularly professionals and politicians. Currently, English teaching in Tanzania operates under total immersion, the success of which has been negligible. Despite this failure, the readiness to switch from English as a MoI to both learners' native language and English (bilingual teaching) in learning English as a foreign language (EFL) and learning using English to improve the quality of education in Tanzania is rather low. Tibategeza (2010) for instance, observes that Kiswahili, a language that both learners and teachers master, is not seen as a useful resource in education but as a problem to be eliminated in the educational settings at post-primary level. Even though the government insists on the existence of a working bilingual education policy programme, the current system in Tanzania features no more than a 'pseudo-bilingual education' policy at best (Biswalo, 2010).

Krashen's study (1997) shows that when schools provide children with quality education in their primary language, they gain two things: knowledge and literacy. He argues that the knowledge that children get through their first language makes the English they hear and read more comprehensible. The relationship between first and second language suggests that effective 
development of the students' literacy skills in their first language provides a conceptual foundation for long-term growth in English literacy skills (Cummins, 2000). Although an attempt to use a mother tongue (Kiswahili) as a MoI in Tanzania is not popular and has been discouraged by most of the parents (Rubagumya, 2003), it has been successful in the teaching and learning process in Zambia (Linehan, 2004) and elsewhere. Educationists and other advocates in Tanzania argue that strategies for quality reform in Tanzania and other African countries have ignored the importance of indigenizing the MoI at all levels of education (Mwinsheikhe, 2003). This failure has rendered various curriculum reforms, especially those targeting secondary level of education unproductive. In assessing the effectiveness of English as a sole MoI in Tanzania, one needs to brainstorm on the following mini-question. Should English lessons allow little use of a mother tongue if it appears to be of great help to students to whom English is an alien language?

According to Benson (2004), mother tongue-based bilingual education increases access to skills and raises the quality of basic education by facilitating classroom interaction, integration of prior knowledge, and experiences with new learning. Moreover, bilingual educational programmes produce solid academic competency at the same time as dual language learning (Research \& Evaluation, 2010). As the learner is educated through his/her own language and later through the global language, the practice of literacy basics is thereby transferred from the second language to the first. There is evidence for the great success of bilingual education in places such as Hawaii (Hawaiian and English) and in mainland United States of America (Spanish and English) (Research \& Evaluation (2010).

\section{Perspectives on LSTT for Teaching and Learning}

Moving from being a novice to an expert is not about learning from talk but rather learning to talk (Daniels, 2001). The learning process is meaningful, engaging, and more participatory when learners are allowed to use the language in which they are richly proficient. If learners are restricted from using a language in which they are proficient, their learning and conceptual learning are constrained to memorizing methods and texts. In language classrooms, the students' first language is a valuable resource for learning a second language; particularly if they have low levels of proficiency in the language they are learning (Clegg \& Afitska, 2011). It is important for extending vocabulary in the second language and for mastering academic registers. Clegg and Afitska (2011) point out that specialized pedagogies they examined have been developed within 
well-resourced education systems for teaching language through the medium of a second language, and rely on extended specialized teacher training. However, the textbook chapters evaluated in our study were intended for poorly resourced secondary schools and students with low levels of proficiency and very restricted vocabulary in English. The premise of LSTT depended on the strategic use of Kiswahili to develop conceptual understanding and knowledge of English for academic purposes.

A baseline study was conducted in 21 schools in Morogoro, Lindi, and Dodoma in 2013 (Barret, Mtana, Osaki, and Rubagumya, 2014). The LSTT materials were introduced and used in schools over a period of 8 weeks. Written and verbal assessments were administered before and after the introduction of the material. The baseline study consisted of a survey of 420 students who were studied to determine their reading ability and knowledge of specialist Mathematics vocabulary. The baseline study also collected information from teachers and students on textbooks availability, use, and preference. Focus group discussions were conducted for each of the three focused subjects in eight schools. Three textbooks-Biology, English, and Mathematicsused in Form One were reviewed for language accessibility, support for language learning, representation of diverse groups, and socio-cultural relevance. The books reviewed included textbooks designed to accommodate Form One needs and selected textbooks written for other country contexts. The findings from the baseline study reflect the following observations: firstly, Form One students were not prepared to learn Mathematics through English as a sole medium of instruction. Secondly, students could not thoroughly identify the meanings of subject specialist vocabulary for Mathematics in English. Thirdly, the translations of keywords in the designed material appeared to guide the students in making connections between what they learned at primary and secondary schools. Fourthly, most of the schools suffered an acute shortage of textbooks. For instance, less than half of schools had a class set of textbooks for Mathematics.

The baseline research was conducted in Tanzania as part of a research project aimed at strengthening innovation and practice in the education of Form One students who are transitioning from Kiswahili-medium primary education to English-medium secondary education. The study was designed to generate recommendations for the design of Biology, English, and Mathematics textbook for Form One after the textbooks currently in use were found to be difficult. The study involved data collection in 21 schools across Dodoma, Morogoro, and Lindi region sand had three main components: A survey of 420 Form One students which was done to 
assess their reading ability; the availability of textbooks in schools and teachers' and students' use of the textbooks; and a review of Biology, English, and Mathematics textbooks used in Form One.

\section{Theoretical Framework}

The study adopted bilingualism theory of Common Underlying Proficiency Model to illuminate the application of bilingual strategy in teaching and learning Mathematics in the actual classroom context. The model was introduced by Cummins (1980a) as quoted in (Baker, 2006) in the form of two icebergs. Ideally, the two icebergs represent two languages and the icebergs are separate above the surface. The two icebergs are fused so that the two languages do not function separately (Cummins, 1980a as quoted in Baker, 2006). Figure 1 indicates the pictorial representation of bilingual proficiency model.

\section{Figure 1: Pictorial Representation of Common Underlying Proficiency Model}

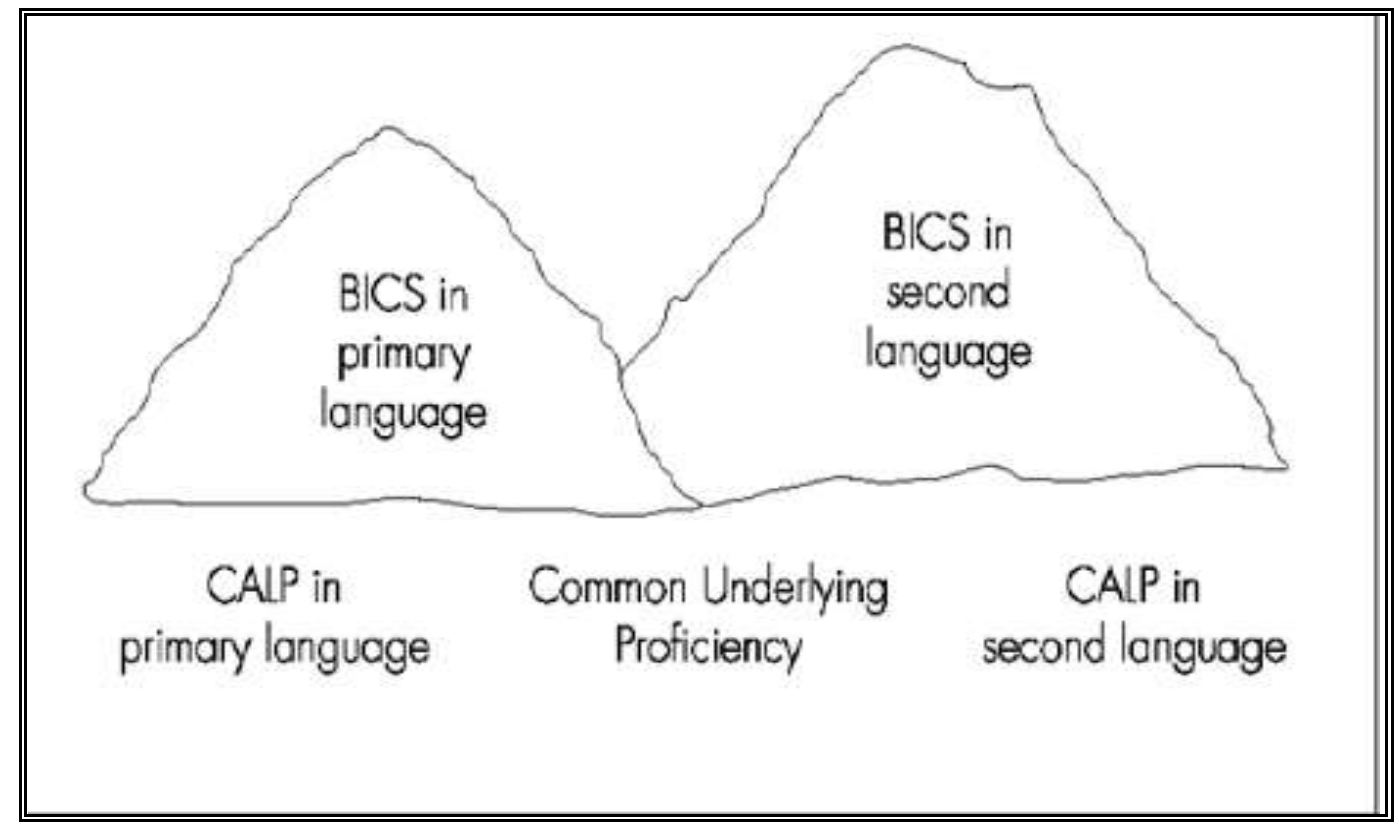

Source: Modified Model Adopted from Cummins (2000)

Cummins summarizes the model in the following ways:

- Information processing skills and educational attainment may be developed through two languages as well as one language. The two languages should, however, be equally successfully developed. 
- The language used by a child in the classroom needs to be sufficiently well developed to be able to process the cognitive challenges of the classroom.

- Speaking, listening, reading, and writing in the first or second language help the whole cognitive system to develop. Nonetheless, if children are made to operate in an insufficiently developed second language (e.g. in a 'submersion' classroom), the system will not function at its best. If children are made to operate in the classroom in a poorly developed second language, the quality and quantity of what they learn from complex curriculum materials and produce in oral and written form may be relatively weak and impoverished.

- When one or both languages are not functioning fully (eg. because of pressure to replace the home language with majority language), cognitive functioning and academic performance may be negatively affected.

For a language to be used as the medium of instruction, it should be well developed to facilitate knowledge generation. That means, both teachers and learners need to be proficient in the language to interact with each other during the teaching and learning process. However, this is contrary to what transpires in the Tanzanian educational system and classroom contexts. In Tanzania, the teaching and learning process is done in the environment whereby the teachers and learners lack sufficient English proficiency (Oluoch, 2006 and Ndabakurane, 2012). A healthy cognitive system is noted for being rich in speaking, listening, reading, and writing skills. If the learners are forced to learn in the language they lack sufficient proficiency, the system will not function to its best and that if the children are made to learn in the poorly developed language, the quality and quantity of what is learnt from the curriculum will obviously be indigent. Poor cognitive functioning and performance may be a result of improper functioning of the language. This is even strongly supported by Sumra and Katabaro (2014) who argue that majority of children entering secondary schools have very low competency in English. According to Sumra and Katabaro, very low competency in English affects students' performance in secondary schools.

In Tanzania, teachers interpret communicative language teaching in terms of exclusive instructional use of the foreign or target language and dishearten students from using their mother tongue. Many schools in Tanzania introduce English campaign rule but it has not achieved the desired results because it is advocated under hostile conditions. For instance, the students are 
given corporal punishment when discovered speaking any other language apart from English particularly in the school compounds. They are also given wooden planks with phrases such as 'I am donkey, I am stupid' etc. to wear around their necks when discovered speaking their ECLs and Kiswahili. It is also common to find phrases such as 'No English No Service' around the school premises to suggest that if a student cannot proficiently express him/herself in English; he/she will not be assisted in any way.

In Tanzania, Mathematics and most of the content subjects become a challenge to most learners since all the terminologies that they learned and applied in Kiswahili for seven years of primary education are dropped from the first day in post-secondary education. Given the students' poor English background, the mathematics textbooks that are used in Tanzanian secondary schools are very complicated for them (Barret, Mtana, Osaki and Rubagumya (2014). Additionally, Frederickson and Cline (2002) argue that for the children being taught in their second language, it is not just the vocabulary of Mathematics that causes difficulty. Rather, the syntax in which mathematical ideas are expressed is often more complex than the children are accustomed to in other areas of the curriculum. While Cognitive Academic Language Proficiency (CALP) is expected to be used in tackling academic challenges in the teaching and learning process as Cummins (2008) argues, the case is different for Tanzanian students whose language proficiency has neither reached Basic Interpersonal Communicative Skills (BICS) nor Cognitive Academic Language Proficiency (CALP) level. Although improved CALP cannot guarantee good performance, it sheds some light on the students' academic wellbeing.

To resolve the issues of language complexity and students' limited English proficiency noted earlier, bilingualism theory is highly preferred and the present study consequently emphasizes Mathematics classroom interaction using bilingual approach as a scaffolding strategy. According to Reiser et al. (2003), scaffolds are instructional supports that allow students to take part in tasks that otherwise would be less accessible or productive and that the scaffold learning materials reduce complexity and highlight concepts and inquiry strategies. Hakuta, Ferdman, and Diaz (1987) define bilingualism as a characteristic of an individual who possesses two linguistic systems. A bilingual, therefore, is a person who is able to speak two (or more) languages at some level of proficiency, but identifying what counts is not a straightforward judgment (Bialystok, 2001). Bialystok emphasizes that to be declared a bilingual depends on how the two languages were learned and to what purposes they are put. For this study, English (a foreign language to the majority of Tanzanians) which is the medium of instruction, on the one hand, and Kiswahili (a 
mother tongue to most Tanzanians particularly those living in coastal areas and those born in towns) which is a resource for both teaching in English on the other, will be emphasized as the languages for teaching and learning Mathematics.

Creese and Blackledge (2010) argue for the effectiveness of the bilingual approach in that trans-language (switching from one language to another) that the teacher and students engage in keeps the task moving and interrupts the usual "initiate, respond, feedback" (IRF) discourses of classroom life. Bilingual education appears to result in performance advantages as compared to submersion or monolingual education (Baker, 2006). The strong need for bilingual teaching is felt when students do not understand the foreign language. The teachers are forced to rely on extensive use of translation from English into the students' familiar language to ease comprehension. Faltis (1996) reported that bilingual teaching means staying in the first language for longer stretches before switching to the other.

Fish and Morford (2012) observe that the benefit of bilingualism is that it is the norm, not the exception, achieves language milestones on time, promotes language and literacy development and cognitive controls processes. Fish and Morford emphasize that bilingual education is more beneficial in that it promotes meta-linguistic awareness. With regard to benefits of bilingual education, the exposure to a first language that is fully accessible encourages the development of language skills and provides opportunities to develop critical thinking and complex reasoning skills that can be applied to literacy development in a second language such as English (Fishand Morford, 2012). Marian, Shook, and Schroeder's study (2013) also affirms that bilingual education is beneficial as it was observed earlier in the majority-language Two-Way Immersion (TWI) students and later in the minority-language TWI students. Marian, Shook, and Schroeder further explain that such results suggest that balanced-language instruction may promote academic achievement in both majority-and minority-language students.

Despite an endless debate regarding using Kiswahili as the MoI at all levels, the Tanzanian government has maintained English as the MoI for secondary schools and at the tertiary level but learning has to continue in the context which is both beneficial and supportive to learners. This is to say that the instructional materials which are currently written in English have also to engage Kiswahili alongside English to communicate mathematical information and make teaching accessible to learners. Faltis (1996) argues that bilingual teaching, especially at the secondary level can help students to develop knowledge and acquire language because it requires a great deal of pedagogical subject matter knowledge as well as a good understanding of bilingual 
methodology. He urges that the integration of language acquisition principles with content teaching become a conscious issue and task for the teachers. The mother tongue should be considered as a potent linguistic resource that needs to be used for academic excellence rather than being looked at as a problem or as a hindrance.

The objective of LSTT is to make textbooks and teaching accessible to foreign language learners in disadvantaged rural schools. The research questions that guided this study are:

1. How can teachers use LSTT to support Mathematics learning in rural community secondary schools?

2. What impact do mathematics textbook designed through LSTT have on language and subject content learning?

\section{Methodology}

\section{Design}

The study is both qualitative and quantitative in nature, conducted in Morogoro, Lindi and Dodoma in 2015. The designed Biology, Mathematics, and English textbooks were piloted and evaluated in the sampled schools. The project focused on English, Mathematics, and Biology because these are amongst priority subjects within Tanzanian secondary education policy. The textbooks designed within this project are intended by Tanzania Institute of Education (TIE) to be suitable for all secondary schools. However, Language Supportive Teaching and Textbooks (LSTT) piloted the textbooks in disadvantaged and low performing rural community schools. Most of the schools under this category were ranked the lowest performers in examinations and serve students who are most disadvantaged by the transition to English-medium. Most of the disadvantaged students live in communities where English is almost not spoken outside the school. So, it is important that the textbooks and teaching support students to access what they have already learned in primary school and learn how to express their knowledge in English. In 2011, Dodoma, Lindi, and Morogoro were ranked $21^{\text {st }}, 12^{\text {th }}$, and $13^{\text {th }}$ respectively out of $21^{3}$ regions in their national Form Four examination results. The majority of learners in three regions speak other ethnic community languages (ECLs) apart from Kiswahili. Therefore, English is a third language to most students. Each region includes rural districts where girls' participation in

\footnotetext{
${ }^{3}$ Four new regions have been created since 2011.
} 
secondary education is much lower than boys and less than $1 \%$ of girls complete Form Four studies qualify for the next educational level.

Eight community rural schools from two regions namely Dodoma (6 schools) and Lindi (2 schools) participated in the study. The choice of the schools was based on the availability of mathematics teachers and their willingness to take part in the study. A total of nine teachers (six from Dodoma Region and three from Lindi Region) participated in the process. The teachers were selected to participate in the study based on their experience in teaching Mathematics. The role of the teachers was to implement or try-out the designed material in the class and eventually to give their comments on the effectiveness of the designed material. Form One students from both Dodoma and Lindi Regions were involved in the study. The role of the students was to learn Mathematics using the adapted material in the classroom context and give their comments on the improvement of the material. The role of the researchers was to ensure effective implementation of the adapted material and solicit the information on the effectiveness of the material from both teachers and students.

The teachers received a two-day orientation on the implementation of the LSTT pedagogy in the classroom. It was followed by the demonstration of one lesson by an expert who was also a researcher. During the classroom lesson implementation, the teachers gave students the printed material to use. The implementation of the LSTT pedagogy was done in four weeks. In the first week, the teachers designed the lesson plans and implemented the lessons in the absence of the researchers. In the second week, the teachers planned the lessons and stated in advance the learning objectives. They shared the lessons planned with the researchers and then implemented the same lessons in the classroom while researchers remained non-participant observers. The teachers were trained to plan and implement the lessons while collecting data.

\section{Instruments}

The study made use of the five data collection tools namely pre- and post-tests (vocabulary and reading comprehension), written tests, verbal tests, and teachers' and students' questionnaires. The study also used classroom observation as a data collection method. The questionnaires were administered to heads of departments to assess the availability and accessibility of the currently used textbooks, the existence of library facilities, and reading schedules for the students. The written test consisted of numbers and algebra problems presented only using mathematical symbols. The test also consisted of eleven basic operation questions and eleven word problem 
questions that could be solved by formulating a simple algebraic expression. The verbal assessment targeted the language learning dimension and focused on the language skills used in the classroom learning for collaborative problem solving, sharing, and discussing ideas. The lesson observation involved recording information on the use of the LSTT textbooks, the kind of activities undertaken, language use, and student participation. Each lesson was followed by an informal interview with the teacher who was invited to comment on the lesson and sections of the textbook that were being implemented. The lesson observations were intended to give professional support to teachers and so the interviews were conducted as supportive mentoring conversations.

\section{Findings and Observations}

\section{Analysis of Written Assessment (Pre-test and Post-test) Results}

The analysis of the post-test and pre-test results for Mathematics was done via descriptive statistics as presented in Table 1.

Table 1: Performance in Pre-test and Post-test in Two Regions

\begin{tabular}{l|ccccc}
\hline & $N$ & Minimum & Maximum & Mean & Std. Deviation \\
& Statistics & Statistics & Statistics & Statistics & Statistics \\
\hline Post-test Mathematics in Lindi & 74 & 8.0 & 58.0 & 35.4 & 12.5 \\
Pre-test: Mathematics in Lindi & 74 & 5.0 & 55.0 & 28.1 & 11.1 \\
$\begin{array}{l}\text { Post-test: Mathematics in } \\
\text { Dodoma }\end{array}$ & 111 & 7.0 & 67.0 & 41.5 & 11.8 \\
$\begin{array}{l}\text { Pre-test: Mathematics in } \\
\text { Dodoma }\end{array}$ & 111 & 10.0 & 64.0 & 36.7 & 10.2 \\
Valid N (list wise) & 55 & & & & \\
\hline
\end{tabular}

Source: LSTT Data (2015)

The observations from Table 1 show that students performed higher in post-tests in the two regions. However, post-test results of Mathematics in Dodoma ( $m=41.5 ; S D=11.8$ ) was higher than that in Lindi. The analysis was done based on the difference in the mean scores between post-test and pre-test for Mathematics in Dodoma and Lindi. The results from the paired sample test for mathematics results in each region are presented in Table 2. 
Table 2: Paired Sample Test Statistics for Scores in Individual Region Scores

\begin{tabular}{|c|c|c|c|c|c|c|c|c|}
\hline & & \multirow[b]{4}{*}{ Mean } & \multicolumn{4}{|c|}{ Paired Differences } & \multirow[b]{4}{*}{$t$} & \multirow{4}{*}{$\begin{array}{r}\text { Sig. (2- } \\
\text { tailed) }\end{array}$} \\
\hline & & & \multirow{3}{*}{$\begin{array}{c}\text { Std. } \\
\text { Deviation }\end{array}$} & \multirow{3}{*}{$\begin{array}{l}\text { Std. } \\
\text { Error } \\
\text { Mean }\end{array}$} & \multirow{2}{*}{\multicolumn{2}{|c|}{$\begin{array}{l}95 \% \text { Confidence } \\
\text { Interval of the } \\
\text { Difference }\end{array}$}} & & \\
\hline & & & & & & & & \\
\hline & & & & & Lower & Upper & & \\
\hline $\begin{array}{l}\text { Pair } \\
1\end{array}$ & $\begin{array}{l}\text { Post-test:Mathematics in } \\
\text { Lindi - Pre-test Mathematics } \\
\text { inLindi }\end{array}$ & 7.4 & 14.1 & 1.6 & 4.1 & 10.6 & 4.573 & 0.000 \\
\hline $\begin{array}{l}\text { Pair } \\
2\end{array}$ & $\begin{array}{l}\text { Post-test:Mathematics in } \\
\text { Dodoma - Pre-test } \\
\text { Mathematics in Dodoma }\end{array}$ & 4.8 & 7.5 & 0.7 & 3.4 & 6.2 & 6.8110 & 0.000 \\
\hline
\end{tabular}

Source: LSTT Data (2015)

The observation from Table 2 shows that the computed $t$-value is above 2.00 with $p<0.05$ suggesting that there is a significant difference in the mean scores between the post-test and pretest means scores for the two regions. The analysis of the post-test and pre-test results was further done by combining the results for all students who sat for Mathematics in Dodoma and Lindi to form another single group. Table 3 presents the paired sample statistics and Table 4 presents the paired sample t-test.

Table 3: Paired Samples Test Statistics for a Combination of Scores in Two Regions

\begin{tabular}{|c|c|c|c|c|}
\hline & & Mean N & $\begin{array}{c}\text { Std. } \\
\text { Deviation }\end{array}$ & $\begin{array}{c}\text { Std. Error } \\
\text { Mean }\end{array}$ \\
\hline \multirow[t]{2}{*}{$\overline{\text { Pair } 1}$} & $\begin{array}{l}\text { Combined Post-test Mathematics inLindi and } \\
\text { Dodoma }\end{array}$ & 39.1185 & 12.4 & 0.9 \\
\hline & $\begin{array}{l}\text { Combined pre-test Mathematics in Lindi and } \\
\text { Dodoma }\end{array}$ & $33.2 \quad 185$ & 11.4 & 0.8 \\
\hline
\end{tabular}

Source: LSTT Data (2015)

The overall observation from Table 3 shows that during LSTT material implementation, students did better in the pre-test $(m=33.2 ; S D=11.4)$. 
Table 4: Paired Samples Test Statistics for a Combination of Post-test Scores and Pre-test Scores in Two Regions

\section{Paired Differences}

\begin{tabular}{|c|c|c|c|c|c|c|c|}
\hline & \multirow{3}{*}{ Mean } & \multirow{3}{*}{$\begin{array}{c}\text { Std. } \\
\text { Deviation }\end{array}$} & \multirow{3}{*}{$\begin{array}{l}\text { Std. } \\
\text { Error } \\
\text { Mean }\end{array}$} & \multirow{2}{*}{\multicolumn{2}{|c|}{$\begin{array}{l}\text { 95\% Confidence } \\
\text { Interval of the } \\
\text { Difference }\end{array}$}} & \multirow{3}{*}{$\begin{array}{rr} & \text { Sig. (2 } \\
t \quad d f & \text { tailed) }\end{array}$} \\
\hline & & & & & & & \\
\hline & & & & & Lower & Upper & \\
\hline $\begin{array}{l}\text { Pair } \\
2\end{array}$ & $\begin{array}{l}\text { Combined post-test } \\
\text { Mathematics in Lindi and } \\
\text { Dodoma - Combined pre-test } \\
\text { Mathematics in Lindi and } \\
\text { Dodoma }\end{array}$ & 5.8 & 10.7 & 0.8 & 4.3 & 7.4 & 7.4184 .000 \\
\hline
\end{tabular}

Source: LSTT Data (2015)

The observation from Table 4 shows that there is a significant difference in the mean scores between post-test and pre-test in the group of students who studied Mathematics in Dodoma and Lindi, $t(184)=7.4 ; \mathrm{p}<0.05$ ). (Reportfindings from the three categories of the test items)

Table 5: Summary of Written Assessment Based on Categories of Test items

\begin{tabular}{l|cccccc}
\hline Total score = 100\% & $\begin{array}{c}\text { PRE-G1 } \\
\mathbf{1 4 2 \%}\end{array}$ & $\begin{array}{c}\text { POS-G1 } \\
\mathbf{1 4 2 \%}\end{array}$ & $\begin{array}{c}\text { PRE-G2 } \\
\mathbf{1 4 0 \%}\end{array}$ & $\begin{array}{c}\text { POS-G2 } \\
\mathbf{1 4 0 \%}\end{array}$ & $\begin{array}{c}\text { PRE-G3 } \\
\mathbf{1 8 \%}\end{array}$ & $\begin{array}{c}\text { POS-G3 } \\
\mathbf{1 8 \%}\end{array}$ \\
\hline $\mathrm{N} \quad$ Valid & 111 & 111 & 111 & 111 & 111 & 111 \\
Mean & $\mathbf{1 6 . 0}$ & $\mathbf{2 0 . 2}$ & $\mathbf{2 0 . 2}$ & $\mathbf{2 0 . 2}$ & $\mathbf{0 . 5}$ & $\mathbf{1 . 0}$ \\
Std. Deviation & 6.2 & 7.3 & 5.2 & 5.3 & 1.6 & 2.9 \\
Skewness & 0.5 & 0.1 & -0.8 & -1.3 & 3.7 & 3.2 \\
Minimum & 4.0 & 6.0 & 0.0 & 0.0 & 0.0 & 0.0 \\
Maximum & 34.0 & 36.0 & 30.0 & 25.0 & 10.0 & 15.0 \\
\hline
\end{tabular}

\section{Source: LSTT Data (2015)}

Key: $P R E=$ pre-test, $P O S=$ post-test $; G 1=$ Written test items consisting of numbers and algebra;

$G 2=$ Written test items consisting problems presented only using mathematical symbol

G3 $=$ The written test items consisting word problem questions that could be solved by formulating a simple algebraic expression 
The LSTT intervention produces a significant improvement in the subject specialism and vocabulary and reading subject specialism text, as evidenced by the scores in the vocabulary section of the mathematics written assessments. However, the relationship between language and mathematics ability was not evident, with no significant improvement in problems that did not require reading or writing English. Further analysis of data set could explore whether and how teachers implemented the sections of the textbooks that dealt with word problems and what language of learning skills students needed to have before decoding word problems. The verbal assessment sessions involved a group of 8 students performing verbal activities under the guidance of the researcher from each school in two sampled regions. The activities offered an opportunity for the students to read, talk, and write some words and sentences so as to explore their language and subject content skills and competencies acquired in the LSTT project. Pre- and post-test verbal assessments were conducted.

During the pre-test assessment, the majority of the students felt shy, fearful to make mistakes, and were recognized as not knowing anything. The students had more difficulties in pronouncing most of the mathematics terms in English because they had few English words. They resorted to Kiswahili or kept silent during the discussions. When the instructions were rendered in English, the teacher gave excessive translations for the students to follow the instructions given and to capture what was intended by the teacher. The findings also indicate that most of the students face great challenges in learning Mathematics through English since they failed to conceptualize most of the mathematical concepts including mathematical operations (addition, subtraction, division, and multiplication) in English. The failure to know Mathematics in English was evidenced by the students' failure in pronouncing the constructed numbers (numbers constructed using cards) in English. They also failed to give the explanations in English using the basic mathematical jargons such as "add more".

During the post-test verbal assessment sessions, the percentage of the students who were able to describe the operations in English ranked high as compared to the pre-test verbal sessions. Having been encouraged by their teacher to describe the operations in English, some of the students described the operations in English although not at the required accuracy. The findings reveal that most of the students could not use English when working in group or pairs as long as the LSTT textbooks offer a wide choice on the language to be used when discussing mathematical concept(s). This implies that most of the students opted for Kiswahili as their most powerful tool 
for discussing mathematical matters. More findings indicate that students in pairs arranged the number perfectly and were able to report back or say the numbers in English although it was after much struggle. The inability of some of the students to make a presentation of their group findings is evidence of difficulties the students had with English. Those who made their presentations in English did so with grammatical errors

Having used LSTT material, the students were capable of expressing their mathematical ideas both in spoken and written forms albeit their grammatical aspects were strained. When invited, they were also able to ask questions although the majority did so using Kiswahili. The fact that the students were able to express their mathematical ideas (right or wrong) in spoken or written English was evident particularly after having used LSTT textbooks. The comparative study between pre-and post-test phase was made by considering the following responses by the students on matchstick pattern 1 activity:

Probe-test phase response

\begin{tabular}{c|cc}
\hline \multicolumn{2}{c|}{ Pre } & \multicolumn{1}{c}{ Post } \\
\hline \multicolumn{2}{c|}{ Probe } & \multicolumn{1}{c}{ Probe } \\
To add more house, your matchsticks & To add more house, Add others 5 matchsticks \\
we... & we... \\
\hline
\end{tabular}

In analyzing the two responses in question, the first response is just a mere noun phrase which cannot convey any meaning since it lacks the verb phrase. Comparatively, the second response conveys meaning since it has the necessary components of the sentence. For instance, it has the word "add" that functions as the verb phrase and the phrase "others 5 matchsticks" that functions as an object of the sentence. It can be established that the LSTT textbooks assisted greatly in transforming the students in various aspects. Having used the LSTT textbooks, most of the students handled different instructions regarding mathematical activities. Having been exposed to LSTT material, the Swahili translations from both the facilitator and researcher were minimal. Given the confidence which the learners had achieved from LSTT textbooks, the learners understood both English and Swahili instructions although it was difficult for them to interact with the subject matter in English as the sole means of communication. 
Knowing Mathematics in English was noted to be a challenge to most students even after having been oriented through LSTT textbook. However, there was a notable improvement for most students although the accuracy in English remains a great challenge. English being a challenge is not unique to students but also to most teachers who demonstrated poor English proficiency in the entire period of LSTT pedagogy implementation. Most of the students could not use English when working in groups or pairs as long as the LSTT textbook offers a wide choice of the language to be used. This implies that most of the students opted for Kiswahili as their most powerful tool for discussing mathematical matters and negotiating meaning. It could be concluded that most of the students gained confidence and interest in Mathematics notably having used LSTT material which proved to be user-friendly because of its shorter and unambiguous sentences and glossaries and because it gave the learners an option to use Kiswahili in the teaching and learning process.

The teachers' and students' questionnaires were used to solicit their views regarding the newly designed LSTT material. The findings revealed that teachers concurred with the strategies in the LSTT material because the students have been given the chance to express themselves both in English and Kiswahili. Interestingly, the teachers suggested that using LSTT material made students love the lesson because they understood both languages. The findings by the students indicated that LSTT pedagogy is effective because it has translated difficult English words and advocates teaching in both English and Swahili. The following verbatim quote from one of the respondents explains the point in question.

...These are beautiful books because they help us know the meaning of words which we did not know before. I would appreciate if all books would have glossaries. I would like to see teachers using Swahili and English in teaching and being allowed to ask questions in Swahili and later make presentations in English.

The students admitted that they used and understood the material easily because they were well translated and that they would like to see other books translated. They also insisted that the material helped them understand English quite easily with the aid of Kiswahili and that they would like to go on with LSTT material because they were well understood. To them, the new books facilitated speaking skills and could easily be read on their own before the subject teachers started teaching. According to students, LSTT materials are better because they give an opportunity for a learner to use Kiswahili especially during the discussion, unlike the currently used textbooks which insist on English in the whole process of English teaching and learning. 


\section{Discussion}

It is important to recognize that Kiswahili is used as MoI and taught as a subject in public primary schools in Tanzania. Conversely, English is a language of instruction in secondary schools and Kiswahili is taught as a subject. Prior to the introduction of LSTT material, the teaching and learning process, as was recommended by the Education and Training Policy of 2014 was done in English only. The learners found it difficult to learn Mathematics in English since they had only a little command of the language. Most of the students arranged the numbers perfectly but had difficulties in how to report back or say the numbers in English. It was very rare for the students to use mathematical jargons like "digits" and "place" or "place value" in English. Such jargons seemed new to learners in terms of their meaning in English.

It is important to recognize that Form One in Tanzania is a transition class from primary to secondary school. It is therefore imperative to observe such a language of instruction challenge in such a transition class. Most of the mathematics concepts are difficult for most of the students, hence a major hindrance to their progress in the subject. Madriñan (2014) reports on the importance of applying a code-switching strategy in order to teach some difficult concepts in any transition class. Madriñan (2014) found out that there was no big difference in students understanding of the activity given in the second language and that given through code-switching. However, the teachers' opinions were that students with a more developed first language and more concrete concepts seemed to transfer their experiences to the new language, making the second language acquisition process easier. LSTT offers an appropriate and gradual transition for the learners who are absolute novices to English to learn with ease. Through a variety of learning experiences, the students are given the ability to acquire the language of instruction through doing, talking, and speaking activities. This exposes students and teachers to English, leading to simplifying English as a second language that breaks the silence during learning (Virginia Department of Education-Division of Instruction, 2004). It was evident that most of the students could not use English when working in groups or pairs. However, the LSTT textbooks offer a choice of the language to be used when discussing mathematical concepts. Such choice enables the students to opt for Kiswahili as the tool for discussing and negotiating meaning. As a result, students started to build confidence and also started using English as a second language during presentations and discussions.

The LSTT material design and implementation draw on experiences from Moschkovich (2007) who insists on the importance of mathematical instructions to be designed focusing on the 
understanding of the relationship between first and second language to facilitate students' learning through the second language. With encouragement from their teacher, some of the students were able to describe the operations in English although not at the required accuracy. The students in pairs managed to arrange the number perfectly and reported back or said the numbers in English although after much struggle. They were able to use mathematical jargons like "digits" and "place" or "place value" in English after using the LSTT materials. They could also express their mathematical ideas in both spoken and written forms albeit their grammatical aspects were far-reaching. When invited, they were also able to ask questions although the majority did so using Kiswahili.

The students acquired a new ability to express their mathematical ideas (right or wrong) in spoken or written English after using the LSTT textbooks. This is an indication that the LSTT materials included a sequential and logical set of activities that helped to engage the students in learning. As Madriñan (2014) has argued, when students are engaged with a proper schedule of learning activities that makes use of code-switching, the lesson runs in a smoother and positive way, helping in making the most of every activity, and thus enriching learning. This was also evident in the interview about the development of the first language on the second language acquisition process. The teachers agreed on the importance of developing the first language in a second language classroom giving an example that when students were learning prepositions of place, it seemed easier for them to learn the concepts up and down, below and beside in the first language and then use them in English (Madriñan, 2014). The LSTT materials used the strategies of giving students the chance to express themselves in both English and Kiswahili. The materials ensured Language Supportive Pedagogy (LSP) through the use of simple English in short sentences, glossaries that translated subject specialist words and difficult words into Kiswahili and illustrations that convey the meaning of the text. It also included structured activities that used Kiswahili as the first language for most learners to learn Mathematics in English. The evidence indicates that the use of Kiswahili in learning mathematical concepts which are widely presented in English has greatly helped the learners translate their mathematical concepts into English.

\section{Conclusion}

Based on the findings and observations, it could be concluded that most of the students gained confidence and interest in Mathematics having used the LSTT materials. The books improved 
students' vocabulary, reading, and writing in English. The schools in Dodoma and Lindi Region saw improvements in different areas including Mathematics subject specialist vocabulary. The teaching and learning objectives were new and challenging to teachers. However, they helped them develop new ways of supporting the mastery of subject content language. Given the confidence which the learners had achieved from LSTT textbooks, the learners could understand both English and Swahili instructions whereas it was difficult for them to interact with the subject matter in English as the sole means of communication.

\section{References}

Allen, K. (2008) Primary School Teachers and the Problems Faced with Teaching the English Language: An Analysis of the Obstacles in the Way of Effective Pupil-centered Teaching and Learning of the English Language in Tanzanian Government Primary Schools with Recommendations.

Baker, C. (2006) Foundation of Bilingual Education and Bilingualism, $4^{\text {th }}$ Edn, Clevedon: Multilingual Matters Ltd. Barret, A.M, Mtana, N., Osaki, K. and Rubagumya, C. (2014) Language Supportive Teaching and Textbooks in Tanzania. Retrieved from research information.bristol.ac.uk//LSTT_baseline on $15^{\text {th }}$ September, 2015.

Biswalo, T.A. (2010) Policy Processes in Relation to Language in Tanzania: Examining Shifts in Language Policy. Published PhD Thesis, University of Illinois.

Benson, C. (2014) The Importance of Mother Tongue-based Schooling for Educational Quality. Retrieved from portal.unesco.org//8301903707a556115649c7e3cf.on $14^{\text {th }}$ September, 2015.

Clegg, J. and O. Afitska (2011). "Teaching and Learning in two Languages in African Classrooms." Comparative Education47(1): 61-77.

Creese, A. and Blackledge, A. (2010) Translanguaging in the Bilingual Classroom: A Pedagogy for Learning and Teaching?, The Modern Language Journal, 94, i, (2010) 0026-7902/10/103-115

Cummins, J. (2000). Language, Power and Pedagogy-Bilingual Children in the Crossfire. Clevedon: Multilingual matters ltd.

Daniels, H. (2001). Vygotsky and Pedagogy. London, RoutledgeFalmer. EdQual (2010) Language of Instruction and Quality of Learning in Tanzania and Ghana. Retrieved from www.edqual.org/publications/policybriefs.html on $15^{\text {th }}$ September, 
2015.

Faltis, C. (1996) Learning to Teach Content Bilingually in a Middle School Bilingual Classroom. In the Bilingual Research Journal.

Fish, S. and Morford, J. P (2012) The Benefits of Bilingualism: Impacts on Language and Cognitive Development.Retrieved from vl2.gallaudet.edu/files/5613/9216/.../researchbrief-7-the-benefits-of-bilingualism.pdf on $2^{\text {nd }}$ May, 2017.

Galabawa, J. C. J. \&Senkoro, F. E. M. K. (2006) Implications of Changing the Language of Instructions in Secondary and Tertiary Education in Tanzania. In Brock-Utne, B., Desai, Z. \&Qorro, M. (eds) Focus on Fresh Data on the Language of Instruction Debate in Tanzania and South Africa. Dar es Salaam: African Minds.

Kajoro, P. 2015 Language Supportive Mathematics Textbooks and Pedagogy with Less Loaded Curriculum for Sustainable Mathematical Literacy in Tanzania. Retrieved from ukfiet2015.exordo.com//Kajoro_UKFIET-2015-Paper-Template.pdf on 30 $0^{\text {th }}$ September, 2015 .

Krashen, S. (1997) Why Bilingual Education? Retrieved from www.usc.edu//education//WhyBilingualEdKrashe. on 14 ${ }^{\text {th }}$ September, 2015.

Lwaitama, A. and Galabawa, J. (2008) Community Secondary Schools: How Long is Their Journey to Quality Education? The paper which was presented on 21st October, 2008, as a contribution to the on-going National Education Debates. Retrieved from www.tenmet.org/.../Community\%20Secondary\%20Sc on15 ${ }^{\text {th }}$ September, 2015.

Malekela, G. A. (2006) Performance in the Primary School Leaving: A Comparison Between Kiswahili and English. In Brock-Utne, B., Desai, Z. \&Qorro, M (eds), Focus on Fresh Data on the Language of Instruction Debate in Tanzania and South Africa. Dar es Salaam: African Minds.

Marian, V., Shook, A. and Schroeder, S. R. (2013) Bilingual Two-Way Immersion Programs Benefit Academic Achievement. In Bilingual Research Journal, 36: 167-186, 2013.

MOEVT . (2014) Education and Training Policy. Retrieved from www.moe.go.tz/index.php?option $=$ com... on $2^{\text {nd }}$ May, 2017.

Moschkovich, J. N. (2007). Bilingual Mathematics Learners: How Views of Language, Bilingual Learners, and Mathematical Communication Impact Instruction. in N. Nassir. and Cobb (Eds.) Diversity, Equity, and Access to Mathematical Ideas. Teachers College Press

Mwinsheikhe, H.M (2003) Using Kiswahili as a Medium of Instruction in Science 
Teaching in Tanzanian Secondary Schools. In Brock-Utne, B., Z. Desai and Qorro, M. (eds) Language of Instruction in Tanzania and South Africa. Dar es Salaam: E\&D Limited.

Ndabakurane, J. J. (2012) Challenges of Teaching and Learning English in Tanzania: A Case of Community Secondary Schools in Ngara District. Unpublished MA Dissertation, University of Dodoma.

Qorro, M.A. (2006) Does Language of Instruction Affect Quality of Education? Retrieved from hakielimu.org/.../document101does_lang_instruc_fct.., site visited on on15 ${ }^{\text {th }}$ September, 2015.

Linehan, L. (2004) Language of Instruction and the Quality of basic Education in Zambia. "Papercommissioned for the EFA Global Monitoring Report 2005, The Quality Imperative".

Research \& Evaluation (2010) Successful Bilingual and Immersion Education

Models/Programs. Retrieved from www.ksbe.edu/_assets/...Bilingual_Immersion_full.p.on 15 th September, 2015.

Sumra, S. and Rajani, R. (2006), Secondary Education in Tanzania: Key Policy Challenges. Working Paper on The Norwegian Post- Primary Education Fund for East Africa (NPEF), 13 - 14 Sept, 2006, Oslo.

Swilla, I.N. (2009) Languages of Instruction in Tanzania: Contradictions between Ideology, Policy and Implementation. In African Study Monographs.

Tibategeza, E. R (2010) Implementation of Bilingual Education in Tanzania: The Realities in the Schools. In Nordic Journal of African Studies.

Vuzo, M. (2010) Exclusion through Language: A Reflection on Classroom Discourse in Tanzanian Secondary Schools. Papers in Education and Development, 29, 14-36.

William, F. (2012) Enabling Science Teaching and Learning in Rural High Schools in Tanzania: Design and Development of Integrated Chemistry Modules (ICM) for Alevel Secondary Education. Unpublished Doctoral Thesis. University of Dodoma, Tanzania.

Madriñan, M.S (2014), The Use of First Language in the Second-Language Classroom:A Support for Second Language Acquisition, Gist Education and Learning Research Journal. 9, 5066. 
Roy-Campbell, Zaline M. (2014). Teaching English as a 'second language' in Kenya and the United States: Convergences and divergences. Global Education Review, 2 (2). 84-97.

Rugemalira, J. M (2005) Theoretical and Practical Challenges in a Tanzanian English Medium Primary School, Africa and Asia No. 5 p. 66-84.

Virginia Department of Education Division of Instruction (2004). Mathematics: Strategies for Teaching Limited English Proficient (LEP) Students.

\section{Acknowledgement}

The authors would like to acknowledge the opportunity and financial support granted by the University of Bristol and the University of Dodoma. The financial support enabled the authors to participate in evaluation study through data collection and analysis. The information obtained from the study helped in writing this research report. 